\title{
Impact of COVID-19 on Stress in Collegiate Student
}

\author{
Kumari Mangalam ${ }^{1}$, Singh Adarsh ${ }^{2}$, Anand Akshay², \\ Arora Sakshi ${ }^{3}$, Sharma Yamini ${ }^{4}$, Sharma Jyoti ${ }^{4}$, Yadav Megha ${ }^{4}$ \\ ${ }^{1}$ Assistant Professor, Galgotias University, Greater Noida, ${ }^{2}$ Student, Galgotias University, ${ }^{3}$ Assistant professor, \\ Manav Rachna International Institute of Research and Studies, ${ }^{4}$ Assistant Professor, Galgotias University Greater \\ Noida
}

\begin{abstract}
Background: A sudden invasion of COVID-19 globally has not only creating fatality but also leading to intolerable psychological pressure in the students as well as other groups. To cope up with this deadly situation many countries declare to be in quarantine and lockdown targeting to limit the transmission. All these situations were creating a lot of curiosity and concern in every individual. This pandemic has increased the level of anxiety and stress in the students.
\end{abstract}

Objectives: This study was aimed to assess the level of stress in students among the Indian population.

Method and Materials: For this an online survey was done using the perceived stress scale (PSS) questionnaire. A total of 475 responses were received from different universities through Google forms which were distributed to them by the various social media platforms.

Results: Out of 475 responses $58.6 \%$ were male and $41.4 \%$ were female. The stress levels identified in students were mostly moderate and high stress with $53.6 \%$ and $35.4 \%$.

Conclusion: The students were preoccupied with the feelings of COVID-19. COVID-19 is creating various types of mental health problems initialling with stress, anxiety, distress insomnia, etc. The thoughts have become so intense that there is a need to intensify the situation. Students as well as people are in need to deal with their stress. This is a need of an hour.

Keywords: Stress, COVID-19, Corona virus, mental health, impact.

\section{Introduction}

Today the pronounced concern and threat in the universe is an invasion of Corona virus aka COVID-19. In December 2019, a public health emergency of global concern an out broke in Wuhan, China which gradually spread to many countries affecting the Mass population of the world ${ }^{1}$.

These viruses generally transmit through human to human transmission and present with clinical manifestation of respiratory and few presents with severe cardiovascular symptoms ${ }^{2}$.

This sudden widespread outbreak is connected with various psychological distresses and presents the features of mental illness ${ }^{3}$. As a result of this life-threatening condition, targets were made to restrict the transmission, early identification, spreading key information regarding awareness of the disease, preventing infection etc ${ }^{4}$.

To achieve the above-mentioned goals many countries implemented the state of lockdown. Although it is contributing to the global economic recession, pause in the production and services and daily routines ${ }^{5}$.

As COVID-19, a new contiguous disease is at its emergence and the way of spreading further creating fear, confusion, anxiety, psychological distress among the public. Lockdown situations have created unnecessary psychological pressure on the students specifically due to the unavailability of medicine and vaccine.

Since mid of March 2020, schools and colleges 
were suspended nationwide. For students, such cessation means a deficit in the exploration of resources, lack of physical activity and their comfort zone. Going to school and colleges acts as a coping system with mental health issues for students. Students are getting irritated, frustrated and short-tempered on the disruption of their daily habits and routines.

Lockdown condition is creating a hostage like condition for everyone. Many students are struggling with their online classes and exams. Exams are getting cancelled and postponed in various countries. Particularly final year students are stressed about their degrees, evacuation of the dormitory, exams, job conditions in the market ${ }^{6}$. The present study was aimed to assess the stress in collegiate students.

\section{Material and Method}

The present study was a cross-sectional, observational study conducted in the students from different Universities of Greater Noida, India. This was an online and self-reported study. An online Perceived Stress Scale questionnaire was developed by using Google forms. Before the questionnaire, a consent form was taken through e-mails and other social media platforms from the subject. The subjects were encouraged and demonstrated about the study after that link was sent to them. That link was auto directed to the information about the study and consent form. After accepting the survey they need to fill their demographic data and then the set of several questions appeared which was to be filled by the participants.

Perceived stress scale is a stress assessment scale which came into existence in 1983 . There were 10 questions in the questionnaire. The questions were supposed to be rated on a 5 point scale ranging from never, rarely, sometimes, fairly often, very often. Score range between $0-13$ is considered as low stress, 14-26 are grouped under moderate stress and 27-40 are grouped under high stress.

Descriptive statistics have been used in the study to analyze the findings. Mean, standard deviation and proportions have been used to estimate the result.

\section{Result}

The online self-reported survey was conducted in the students of different universities of Greater Noida, India. A total of 475 responses were recorded. All students were between 18- 24 years of age and Indian origin. The study was limited for the student who had any type of psychological and mental disorder. The students who know the English language were included in the study.

The mean age was $22.45 \pm 3.95$ Years. Among the total subjects $58.6 \%$ were male and $41.4 \%$ were female. Out of total strength, (fig. 1) $53.6 \%$ $(19.26 \pm 3.19)$ participants were moderately stressed, $10.7 \%(10.33 \pm 2.45)$ were having a low stress and rest $35.57(33.72 \pm 3.04)$ were highly stressed.

Table 1: Showing various stress level in male and female

\begin{tabular}{|l|c|c|c|c|}
\hline & & Low Stress (0-13) & Moderate stress (14-26) & High stress (27-40) \\
\hline Male & $58.6 \%(279)$ & $12.18 \%$ & $55.9 \%$ & $31.8 \%$ \\
\hline Female & $41.4 \%(196)$ & $7.14 \%$ & $52 \%$ & $40.8 \%$ \\
\hline Total & $\mathbf{4 7 5}(\mathbf{1 0 0} \%)$ & $\mathbf{1 0 . 7 \% ( 1 0 . 3 3 \pm \mathbf { 2 . 4 5 } )}$ & $\mathbf{5 3 . 6} \%(\mathbf{1 9 . 2 6} \pm \mathbf{3 . 1 9})$ & $\mathbf{3 5 . 5 7}(\mathbf{3 3 . 7 2} \pm \mathbf{3 . 0 4})$ \\
\hline
\end{tabular}

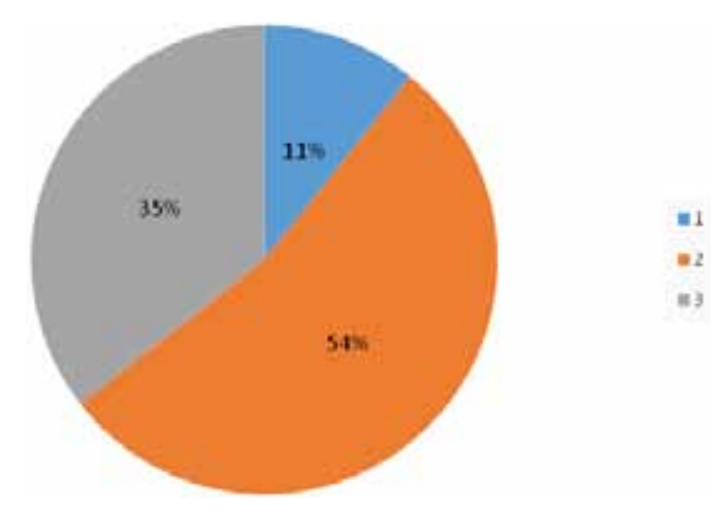

Fig 1. Showing overall stress in the students due to Covid-19 


\section{Discussion}

COVID-19 is considered pandemic globally and the most stressful situation for the whole human race. People of any caste, race, religion and community are facing a spectrum of challenges during this phase. Many times Lack of acknowledgment generally leads to an intolerable reaction, which may further adversely affect mental conditions. Impacts are so intensified, that they may severely affect the mental, physical and social well-being of any community. The mental state initially comes in terms of fear, anxiety, behaviour change and ultimately leads to stress.

Hence this study was attempted to assess stress in collegiate students. COVID-19 infection is a highly contagious disease and simultaneously affects a large population ${ }^{7}$.

Every pandemic disease has its specific characteristics concerning causality, advancement and to control the measures. It is important to provide instruction, education and acknowledgment regarding the prevention and spreading of disease ${ }^{8}$. Responses to epidemic partly depend on the mortality rate. Various studies have shown that the outbreak of many infectious diseases including severe acute respiratory syndrome (SARS) 2003 epidemic and pandemic novel influenza A (H1N1) 2009 has adversely affect mental health. Several post-traumatic stress disorder (PTSD), Psychological suffering along with anxiety and depression have been reported among populations that were exposed to mass conflict and displacement. Similar findings of high levels of psychological distress were recorded during the outbreak of the Ebola virus in Guinea and Sierra Leone in all Dominance countries 9 .

Ginger reported that $88 \%$ of the workers are moderate to severe stress for the last 4-6 weeks. Quarantine, social distancing and separation may be leading to psychologically distressing for many people ${ }^{10}$.

Our participants have not infected with COVID-19 still more students were highly and moderately stressed and they need to cope up with their stress otherwise it will further lead to many cardiovascular problems. It can be assumed that, people who are infected with COVID-19 suspected to have highly stressed and compromised mental health.

In this time of crisis it is crucial to cope with stress, anxiety, depression and other psychological disorder otherwise it may transform into severe distress leading to denial thoughts like hopelessness, dullness, failing and suicidal feelings ${ }^{11}$.

Limitations this study is limited for the student who had Smartphone, e-mail IDs, internet issue and the ability to English. This study represents the data of only the educated population so it should not be generalized to the whole population.

\section{Conclusion}

COVID-19 is creating fatality, economic defoliation, psychological trauma, etc. It is clear that this pandemic has led to a vigorous and multifaceted response from students, psychiatrists and allied professionals and for that mental health issues should be taken into consideration at multiple domains and in every age group and populations. During the COVID-19 pandemic situation, students as well as people are in need to deal with their stress.

\section{Source of Funding: None}

\section{Conflict of Interest: None}

Ethical Clearance: Institutional Committee members have approved.

\section{References}

1. WHO, Pneumonia of Unknown Cause - China. https://www.who.int/csr/don/05-january-2020pneumonia-of-unkown-cause-china/en/(Accessed 3.31.20)

2. Zheng YY, Ma YT, Zhang JY, Xie X. COVID-19 and the cardiovascular system. Nature Reviews Cardiology. 2020 May;17(5):259-60.

3. Bao Y, Sun Y, Meng S, Shi J, Lu L. 2019-nCoV epidemic: address mental health care to empower society. The Lancet. 2020 Feb 22;395(10224):e378.

4. WHO. Rolling Updates on Corona virus Disease (COVID-19). https://www.who.int/emergencies/ diseases/novel-coronavirus-2019/events-as-theyhappen (Accessed 3.31.20)

5. Roy D, Tripathy S, Kar SK, Sharma N, Verma SK, Kaushal V. Study of knowledge, attitude, anxiety $\&$ perceived mental healthcare need in Indian population during COVID-19 pandemic. Asian Journal of Psychiatry. 2020 Apr 8:102083.

6. Lee J. Mental health effects of school closures 
during COVID-19. The Lancet. Child \& Adolescent Health. 2020 Apr 14.

7. WHO, Coronavirus Disease 2019 (COVID-19) https://www.who.int/docs/default-source/ coronaviruse/situation-reports/20200330-sitrep70-covid-19.pdf?sfvrsn=7e0fe3f8_4Situation Report -70

8. Johnson EJ, Hariharan S. Public health awareness: knowledge, attitude and behaviour of the general public on health risks during the H1N1 influenza pandemic. Journal of Public Health. 2017 Jun 1;25(3):333-7.
9. Jalloh MF, Li W, Bunnell RE, Ethier KA, O’Leary A, Hageman KM, Sengeh P, Jalloh MB, Morgan $\mathrm{O}$, Hersey S, Marston BJ. Impact of Ebola experiences and risk perceptions on mental health in Sierra Leone, July 2015. BMJ Glob Health. 2018; 3 (2): e000471. Epub 2018/03/17. https:// doi. org/10.1136/bmjgh-2017-000471 PMID: 29607096;

10. Matthew Gavidia, https://www.ajmc.com/ newsroom/how-has-covid19-affected-mentalhealth-severity-of-stress-among-employees.

11. http://nimhans.ac.in/wp-content/uploads/2020/04/ MentalHealth IssuesCOVID-19NIMHANS. 